\title{
Surface properties and fatigue failure analysis of Alloy 718 surfaces milled by Abrasive and Plain Waterjet
}

\author{
A. Rivero ${ }^{1}$, A. Alberdi ${ }^{1 *}$, T. Artaza ${ }^{1}$, L. Mendia ${ }^{2}$ A. Lamikiz ${ }^{3}$ \\ (1) Industry and Transport Division, Tecnalia Research \& Innovation, Paseo Mikeletegi 7 - Parque Tecnológico E-20009 \\ Donostia, Spain \\ (2) Technological Services Division, Tecnalia Research \& Innovation, Paseo Mikeletegi 2 - Parque Tecnológico E- \\ 20009 Donostia, Spain \\ (3) Department of Mechanical Engineering, University of Basque Country UPV/EHU, Alameda Urquijo s/n, 48013 \\ Bilbao, Spain \\ *amaia.alberdi@tecnalia.com, ORCID: 0000-0003-2225-993X
}

\begin{abstract}
This work analyzes the surfaces obtained in Alloy 718 when they are milled by Abrasive Waterjet (AWJ) at different conditions, and the effect of main process parameters on the characteristics of these surfaces. This analysis revealed that all surfaces have a homogeneous roughness in the transversal and the longitudinal directions, present embedded abrasive particles and have hardened about $50 \%$ with respect to the untreated bulk Alloy 718 . On the other hand, Plain Waterjet (PWJ) technology was used for removing the abrasive particles embedded in surfaces of Alloy 718 milled previously by AWJ technology. The effect of this process on the surface characteristics is also analyzed. For all tested conditions, this technology removed all the particles embedded in the surface. In addition, the PWJ technology process in general smoothened the surfaces produced by AWJ milling and it also released nearsurface stress. Finally, fatigue tests revealed lower performance of the treated specimens in comparison to untreated specimens, due to crack-like surface irregularities introduced by the treatments.
\end{abstract}

Keywords: Waterjet, Alloy 718, AWJ, PWJ, milling, fatigue

\section{NOMENCLATURE AND ABBREVIATONS}
AWJ Abrasive Waterjet
BEI Backscattered Electron Image
EDS Energy Dispersed Spectrometry
MRR Material Removal Rate
PWJ Plain Waterjet
SEM Scanning Electron Microscope
f $\quad$ Lateral feed
$\dot{\mathrm{m}}_{\mathrm{a}} \quad$ Abrasive mass flow rate
$\mathrm{N} \quad$ Cycles to Failure
n Number of passes
$\mathrm{p}$ Pressure
$\mathrm{R}_{\mathrm{a}} \quad$ Average roughness 


\section{INTRODUCTION}

The number of aircrafts will be highly increased over the next 20 years according to the Airbus Global Market Forecast [1]. Regarding the increase of aircrafts (3.7\% per year) resulting from the growth of air traffic per year (4.7\% per year), in 2034 more than 38.000 aircrafts are estimated to be in service. Of these, 19.000 are necessary due to growth, whereas 13.000 will be replacement of actual airplanes, leading to 32.000 new aircrafts which need to be built.

This leads to a significantly increasing necessity of manufacturing high-temperature resistant materials used in the turbo-machinery. Heat-resistant superalloys such as Alloy 718 are commonly used in the aerospace sector, thanks to their unique combination of properties like high strength at elevated temperatures, resistance to chemical degradation and wear resistance. The ability to maintain these properties at elevated temperatures severely hinders the machinability of these alloys. Thus, they are generally referred as difficult-to-cut alloys. Most problems encountered during machining are due to heat generation, mainly during the deformation process and friction at the tool-chip and tool-workpiece interfaces, and the consequent high temperatures associated with it. Other characteristics of aerospace superalloys include their austenitic matrix which makes them harden rapidly, their ability to react with tool materials under atmospheric conditions, their tendency to form built-up edge and to weld to cutting tools and the presence of abrasive carbides in their microstructure [2]. The associated manufacturing cost is high because of low material removal rates and rapid tool wear. The machining of these alloys is characterized by low productivity and low process stability as a result of their physical and mechanical properties [3, 4]. Major problems during the machining of these materials are very high thermal and mechanical tool loads. This results in low applicable cutting speeds due to excessive tool wear, long machining times, and thus high manufacturing costs $[5,6]$.

The Abrasive Waterjet (AWJ) technology has a great potential for machining heatresistant superalloys $[7,8]$. Its main advantages for manufacturing these materials are its low tool wear, since it is a non-contact process and its flexibility for application to different processes like cutting, milling, turning or peening.

One of the disadvantages of the use of AWJ technology for machining metal parts is the embedment of the abrasive particles in the machined surface, since it may be detrimental for the fatigue life of the components [9]. In [10], it was demonstrated that AWJ cutting process reduced significantly the fatigue life of Ti6Al4V specimens cut by AWJ compared to machining, and that an improvement in cutting quality level led to an increase in the fatigue life. On the other hand, Huang et al. [11] demonstrated that it is possible to use the plain waterjet (PWJ) technology for cleaning the surfaces of Ti-6Al$4 \mathrm{~V}$ with an alpha case layer machined previously with AWJ technology, but fatigue behavior of specimens was not analyzed. In addition, Arola et al. [12] demonstrated that both AWJ and PWJ peening, which is similar to waterjet milling process, produce compressive residual stresses in Titanium alloy samples, and that AWJ peening can 
improve the fatigue life of the components of AISI 304 and Ti6AI4V [13]. On the other hand, Azhari et al. [14] studied the effect of applying multiple passes of PWJ peening in AISI 304, and concluded that the compressive residual stresses increase with a higher number of passes and also the resulting surface hardness. They also observed an increase of the roughness of the surface, so that there are a lot of potential crack initiation sites which leads to the decrease of fatigue strength. Lieblich et al. [15] also found that PWJ introduces compressive residual stresses to Ti6Al4V specimens, but that it reduces the fatigue life comparing with grit blasting process.

This work analyzes the surfaces obtained in Alloy 718 when they are milled by AWJ at different conditions of pressure, stand-off distance, abrasive mass flow rate and lateral feed of the tool path, in terms of surface roughness, sub-surface hardening and the degree of embedded abrasive particles. The PWJ technology was used for removing the abrasive particles embedded in surfaces of Alloy 718 milled previously by AWJ technology. The effect of this process on the surface characteristics is also analyzed. Finally, the effect of the AWJ and PWJ milling on the fatigue life of components subjected to these processes was also studied by testing samples manufactured by 3 different processes: i) conventionally machined; ii) conventionally machined and milled by AWJ; and iii) conventionally machined, milled by AWJ and post-processed by PWJ.

\section{EXPERIMENTAL PROCEDURE}

\subsection{Materials and equipment}

All experimentation was carried out in the Byjet $L 2030 \AA$ waterjet cutting machine equipped with the Bypump 50APC® high pressure pump, which can reach a maximum working water pressure of $360 \mathrm{MPa}$. An orifice nozzle of $0.25 \mathrm{~mm}$ in diameter and a focusing tube of $0.76 \mathrm{~mm}$ were used as a tool. Same machine was employed for both AWJ and PWJ technologies, with the difference of no adding any abrasive particle to the water jet in the case of PWJ.

The material used is annealed Nickel based Alloy 718 of a thickness of $3.2 \mathrm{~mm}$, with a ultimate tensile strength of $965 \mathrm{MPa}$, a yield strength of $562 \mathrm{MPa}$ and an elongation of $44 \%$.

\subsection{Milling of Alloy 718 surfaces by AWJ}

Alloy 718 surface areas of $30 \times 20 \mathrm{~mm}$ were milled by AWJ using different processing conditions. As a standard test condition, a pressure of $360 \mathrm{MPa}$, a traversal feed rate of $15 \mathrm{~m} / \mathrm{min}$, a mass flow rate of $300 \mathrm{~g} / \mathrm{min}$ and a stand-off distance of $90 \mathrm{~mm}$ were stablished. In order to analyze the effect of these parameters, each was varied at other two levels stated in Table 1, which resulted in 9 different testing conditions. The lateral feed of the toolpath was fixed for each stand-off distance, in order to maintain similar overlapping areas between two adjacent tracks. In addition, the direction changes were programmed to be made outside the material surface in order to avoid the effects produced by the acceleration and deceleration of the cutting head (Figure 1). 


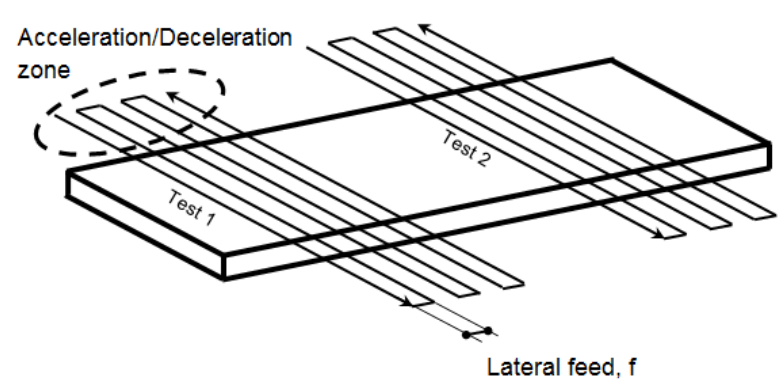

(a)

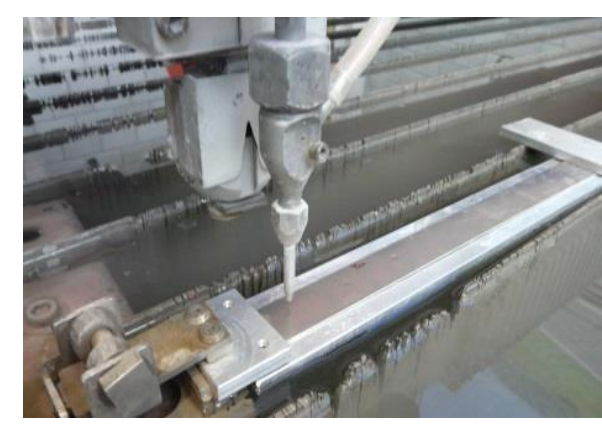

(b)

Figure 1. (a)Milling tool paths; (b) Experimental set-up;

\subsection{PWJ cleaning}

For demonstrating the viability of removing embedded abrasive particles by PWJ technology, first, 9 different areas of $20 \times 30 \mathrm{~mm}$ were milled in Alloy 718 by AWJ technology employing standard conditions $(p=360 \mathrm{MPa}, \mathrm{s}=90 \mathrm{~mm}, \mathrm{v}=15 \mathrm{~m} / \mathrm{min}$ and $\dot{\mathrm{m}}_{\mathrm{a}}=300 \mathrm{~g} / \mathrm{min}$ ), whose average area with embedded abrasive particles resulted in $19.434 \%$. Then, these areas were post-processed by PWJ technology for cleaning. As a standard post-processing condition, a pressure of $360 \mathrm{MPa}$, a stand-off distance of $10 \mathrm{~mm}$, a traversal feed rate of $500 \mathrm{~mm} / \mathrm{min}$, and 1 pass was stablished. In order to analyze the effect of these parameters, each of these parameters were also varied at other two levels stated in Table 1, resulting in 9 different testing conditions.

Table 1. Definition of levels for each process parameter

\begin{tabular}{|c|c|c|c|c|c|c|}
\hline \multirow{2}{*}{ Process parameter } & \multicolumn{3}{|c|}{ Levels for AWJ milling } & \multicolumn{2}{c|}{ Levels for PWJ post-processing } \\
\cline { 2 - 7 } & $\mathbf{1}$ & $\mathbf{2}$ & $\mathbf{3}$ & $\mathbf{1}$ & $\mathbf{2}$ & $\mathbf{3}$ \\
\hline$\dot{\mathbf{m}}_{\mathrm{a}}[\mathbf{g} / \mathrm{min}]$ & 150 & 300 & 450 & - & - & - \\
\hline $\mathbf{p}[\mathrm{MPa}]$ & 160 & 260 & 360 & 160 & 260 & 360 \\
\hline $\mathbf{v}[\mathrm{mm} / \mathrm{min}]$ & 5000 & 10000 & 15000 & 100 & 500 & 900 \\
\hline $\mathbf{s}[\mathrm{mm}]$ & $10(\mathrm{f}=0.2 \mathrm{~mm})$ & $50(\mathrm{f}=0.6 \mathrm{~mm})$ & $90(\mathrm{f}=1 \mathrm{~mm})$ & 10 & 50 & 90 \\
\hline $\mathbf{n}[-]$ & - & - & - & 1 & 2 & 4 \\
\hline
\end{tabular}

\subsection{Surface analysis}

The obtained surfaces were measured and analyzed in terms of roughness, subsurface hardening and the embedment of abrasive particles. For measuring the topography of textured surfaces a Leica DCM 3D optical surface metrology system was used. The surface average roughness was evaluated in longitudinal and traversal direction to the machining path, using a Gaussian filter with a cut-off length of $0.8 \mathrm{~mm}$. For measuring the sub-surface hardness, polished cross sections were obtained and a Future Tech FM-800 micro-hardness tester was used starting at $1500 \mu \mathrm{m}$ far from the eroded surface up to a distance of about $20 \mu \mathrm{m}$ close to it. Finally, surfaces were also analyzed by SEM microscope. Backscattered electron images (BEI) are taken for analyzing the percentage of the area embedded by abrasive particles. The images are analyzed using the software ImageJ according to the procedure described by Huang et 
al. [11], by filtering out the darkest zones corresponding to abrasive particles using a suitable threshold (Figure. 2). The images were obtained and analyzed in three different positions of the samples.

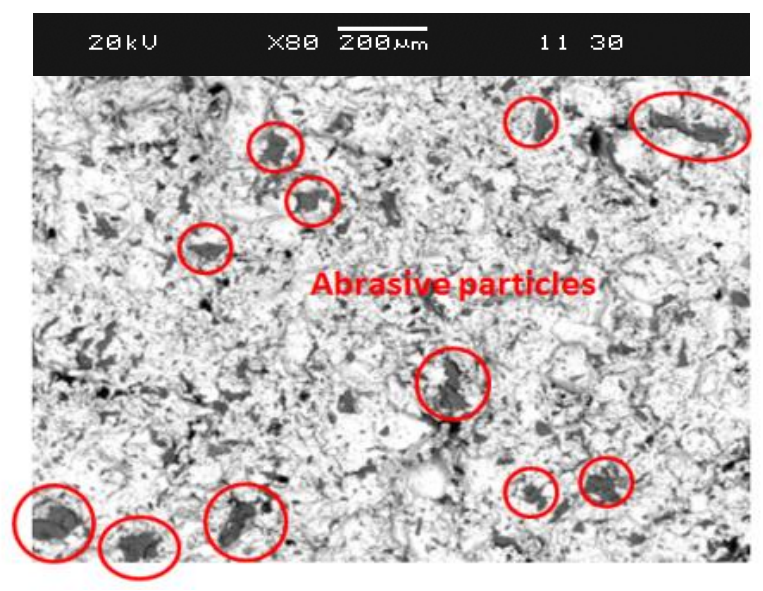

Figure. 2. BEI image of INCO 718 surface milled by AWJ.

\subsection{Fatigue testing}

A total of 26 fatigue samples were machined conventionally for fatigue testing: 12 of them were milled by AWJ using the standard processing conditions, 8 of them were milled by AWJ and post-processed by PWJ using standard conditions, and finally, 6 of them were not treated. All samples were subjected to a fatigue testing in INSTRON 8032 machine for which different stresses were applied.

In order to find the crack origin location a macroscopic inspection by a stereoscopic microscope, followed by a microfractographic analysis by SEM and metallographic analysis by Light Microscopy has been performed.

\section{RESULTS AND DISCUSSION}

\subsection{Characteristics of surfaces milled by AWJ}

The surfaces milled by AWJ show similar characteristics to grit-blasted surfaces. The obtained average roughness values and the effect of process parameters are shown in Figure 3. The results showed that the longitudinal and transversal average roughness have similar values, no effects of the tool path are observed. Thus, the surfaces present a homogenous texture. The average roughness of the surfaces varies from $9 \mu \mathrm{m}$ to $15 \mu \mathrm{m}$, which are in agreement with the results obtained by Sadasivan et al. [16] in Alloy 718. In addition, the abrasive mass flow rate, the pressure and the stand-off distance have a significant influence on the average roughness. In this study, the employed AWJ milling conditions corresponds to high traverse feed rates, where the eroded depths are low and thus, particle-substrate impact occurs at normal angles. In this case, the particle performs as an indenter with the depth and area of indentation dependent on the shape and size of the particle and its velocity [17]. Low velocity impact and small particles result in small indentations in the target material and thus, low values of surface roughness. At higher particle velocities and greater particle sizes, the indentations are correspondingly deeper and the surface roughness increases. According to the Bernoulli's law and the simple momentum-transfer model [18], there is 
a square-root relation between abrasive-particle velocity and the pressure. Therefore, an increase in the pressure leads to an increase in the surface roughness as observed in Figure 3b. In addition, the results obtained in this study show that when increasing the abrasive mass flow rate, the roughness decreases. This can be explained by taking into account that for greater abrasive mass flow rate, there exist more collisions between different abrasive particles and their kinetic energy is wasted [19]. In addition, this collision also leads to a reduction in the size of the abrasive particles. In the case of the stand-off distance, a significant increase of the roughness was observed when increasing the stand-off distance from 10 to $50 \mathrm{~mm}$. On the contrary, the roughness is reduced when increasing it from 50 to $90 \mathrm{~mm}$. This may indicate that there exists an optimum for the stand-off distance where the momentum transfer from the water jet to the abrasive particles is the maximum, thus, the abrasive particles reach the highest possible velocity. If higher stand-off distances are employed, the abrasive particles start decelerating, decreasing the velocity impact and therefore, the roughness. This statement is in agreement with the model obtained in [20] for milling Aluminum 7075 by AWJ, which indicates that there exists an optimum value for the stand-off distance equal to $33 \mathrm{~mm}$ which maximizes the MRR for similar processing conditions $(p=360$ $\mathrm{MPa}, \dot{\mathrm{m}}_{\mathrm{a}}=300 \mathrm{~g} / \mathrm{min}$ and $\left.\mathrm{v}=800 \mathrm{~mm} / \mathrm{min}\right)$ used in this study $\left(\mathrm{p}=360 \mathrm{MPa}, \dot{\mathrm{m}}_{\mathrm{a}}=300 \mathrm{~g} / \mathrm{min}\right.$ and $v=5000 \mathrm{~mm} / \mathrm{min}$ ). In this model it was not possible to use higher values of the traverse feed rate because they were out of the experimental window used in that study. However, similar conclusions would be obtained for higher traverse rates, since the velocity impact and the shape and size of the abrasive particles is independent to the traverse feed rate. The latter, is also reflected in Figure $3 b$, which indicates that no clear effect of the traverse feed rate was observed.

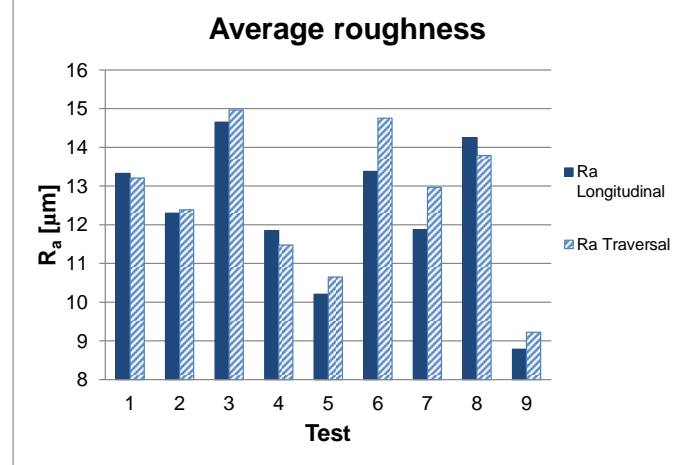

(a)

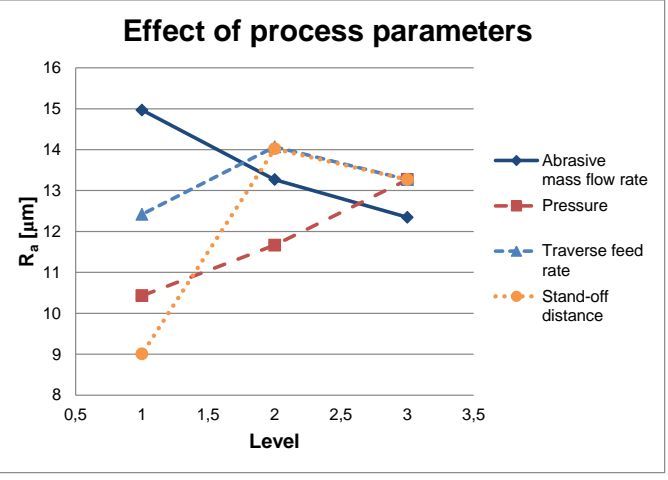

(b)

Figure 3. Average roughness of surfaces milled by AWJ (a) Longitudinal and traversal directions; (b) Effect of the process parameters

According to Figure 4, a hardness gradient is evident starting from a distance of around $300 \mu \mathrm{m}$, and increasing with proximity to the surface up to 40-45 HRC. This increase corresponds to a hardening of about $50 \%$ with respect to the untreated bulk Alloy 718 (20-25 HRC). The AWJ process is a combination of erosion and localized plastic deformation produced by abrasive particles impacts. The plastic deformation leads to an increase in the subsurface hardness and to compressive residual stresses. According to the literature [13], it is expected that the hardness gradient coexists with a significant gradient of compressive residual stresses. Although residual stressed were not measured, the curvature of the milled samples indicated a compressive residual stresses in the milled surface (Figure 5). Regarding the effect of process parameters, 
no significant effects of process parameters were observed within this experimental study. According to Arola et al. [12], the residual stresses are dependent to the pressure and to the abrasive particles size, which means that the same parameters which increase the roughness also increase the residual stresses and the sub-surface hardness. Therefore, a correlation between the surface roughness and sub-surface hardness may be observed. However, neither in this study nor in the study made by Huang et al. [11] this correlation was observed.

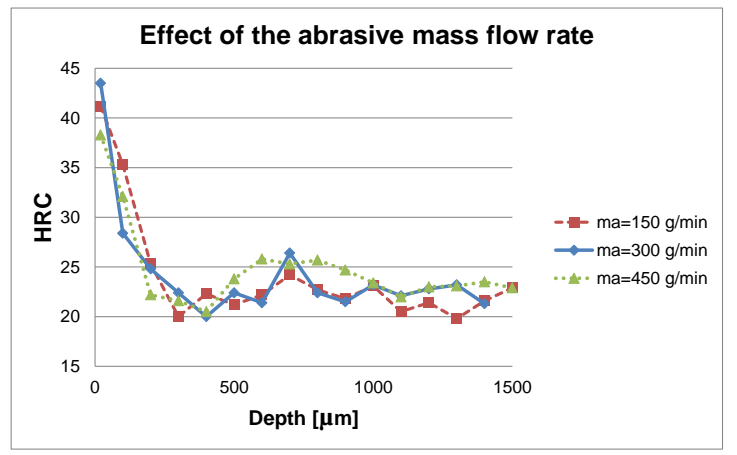

(a)

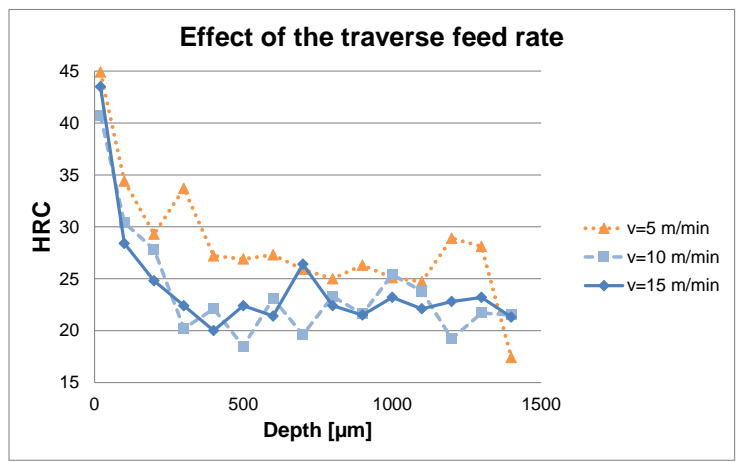

(c)

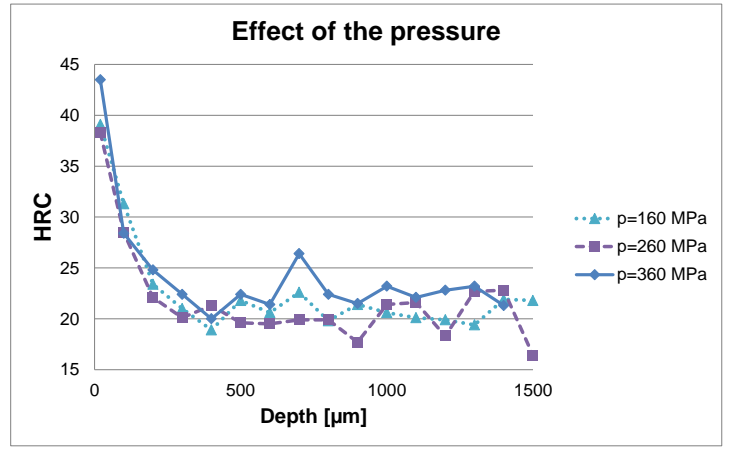

(b)

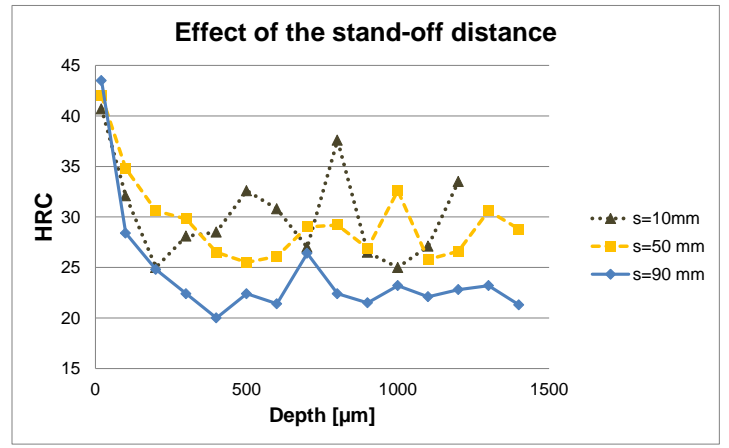

(d)

Figure 4. Effect of process parameters on the subsurface hardness in surfaces milled by AWJ: (a) abrasive mass flow rate; (b) pressure; (c) traverse feed rate; (d) stand-off distance.

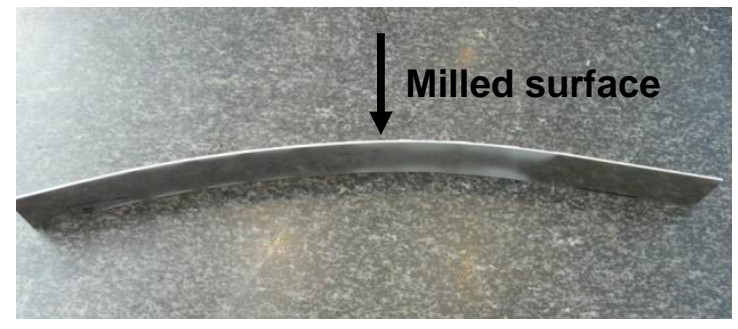

Figure 5. Curvature of the samples milled by AWJ

Finally, as occurred in grit blasting process, substrates subjected to AWJ milling also present abrasive embedment. Figure 6 shows the results obtained and the effect of process parameters on the embedded area. The results show that all surfaces presented embedded abrasive particles, and that the surface area embedded with abrasive particles varies from $5 \%$ to $20 \%$. In addition, when increasing the pressure, the traverse feed rate and the stand-off distance, the area percentage with embedded abrasive particles increases. On the other hand, the highest level of particle embedment occurred for an abrasive mass flow rate of $300 \mathrm{~g} / \mathrm{min}$. 


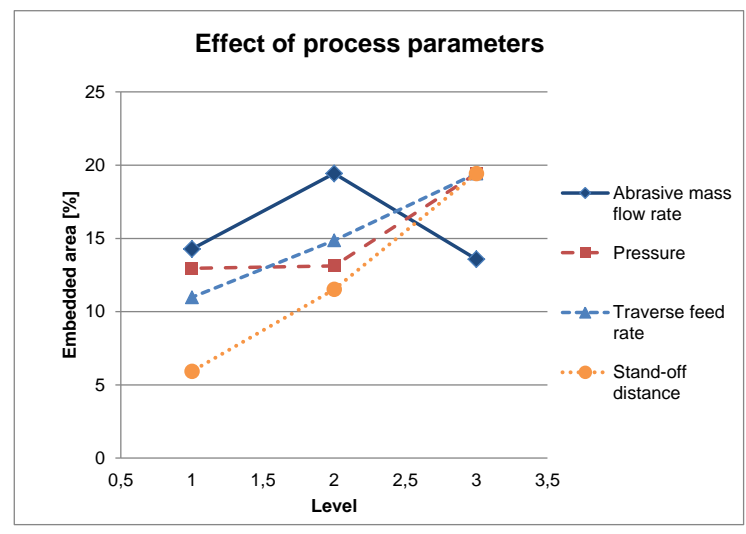

Figure 6. Effect of the process parameters on abrasive particles embedment when milling by AWJ

\subsection{Effect of PWJ post-processing}

The obtained surfaces are macroscopically similar to the surfaces obtained when milling by AWJ, they present a homogenous texture. The average roughness of the surfaces varies from $9 \mu \mathrm{m}$ to $18 \mu \mathrm{m}$ and in general, the PWJ post-processing reduced the roughness produced during AWJ milling (Figure 7a). This is because water droplets erode and deform the peaks and valleys produced by abrasive particles, which are the most sensitive areas of failure against the impact of water droplets. Thus, the PWJ tends to smoothen the surfaces milled by AWJ. However, this smoothening depends on the process parameters used during PWJ. According to Taylor [21], the roughness in PWJ is proportional to erosion of the substrate, and therefore it is proportional the hydraulic energy of the jet and the exposure time. When using low hydraulic energy (low pressure and high stand-off distance) and low exposure time (high traverse feed rate and low number of passes), the jet is not able to erode and deform the substrate, thus, very little reduction in the roughness is observed (Figure $7 \mathrm{~b}$ ). On the contrary, when using high hydraulic energy (high pressure and low stand-off distance) and high exposure time (low traverse feed rate and high number of passes), this reduction is more evident since the jet is able to erode and deform more peaks produced by abrasive particles in the previous processing step. An increase in the roughness is observed when very low traverse feed rate is used $(100 \mathrm{~mm} / \mathrm{min})$. This is because the roughness produced when using these processing conditions is higher than the roughness produced by AWJ milling. Thus, the resulting average roughness is the one corresponding to the PWJ processing.

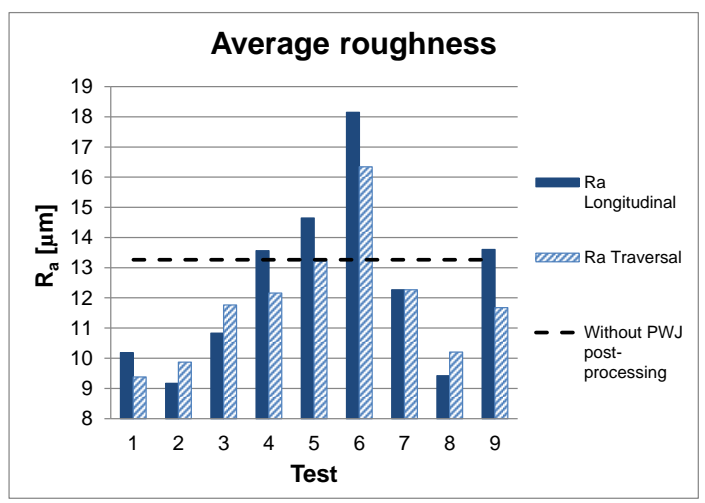

(a)

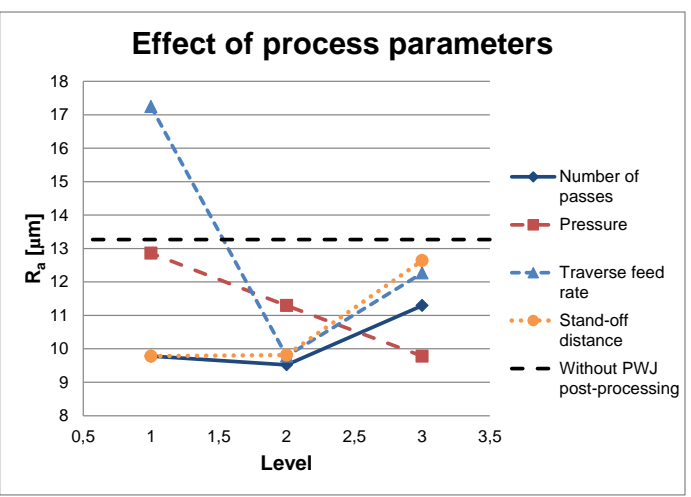

(b)

Figure 7. Average roughness of surfaces post-processed by PWJ (a) Longitudinal and traversal directions; (b) Effect of the process parameters 
The PWJ post-processing also reduced the subsurface hardness of the samples milled by AWJ. The material removal eroded by water droplets during PWJ post-processing lead to relief near-surface stress, and therefore, this erosion is the responsible of the reduction of the sub-surface hardness (Figure 8 ). This reduction is more evident when high hydraulic energies (high pressure and low stand-off distance) and high exposure times (low traverse feed rate and high number of passes) are used.

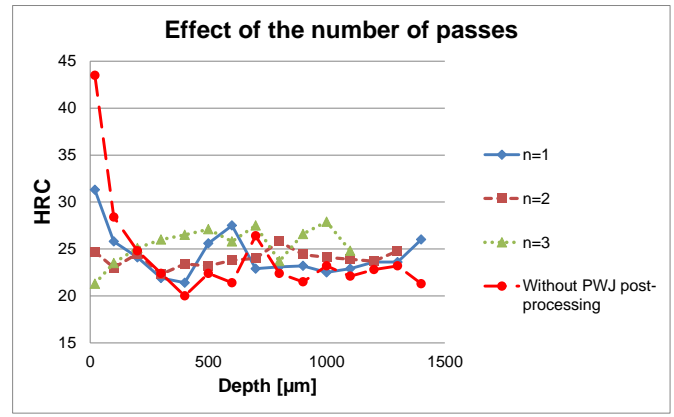

(a)

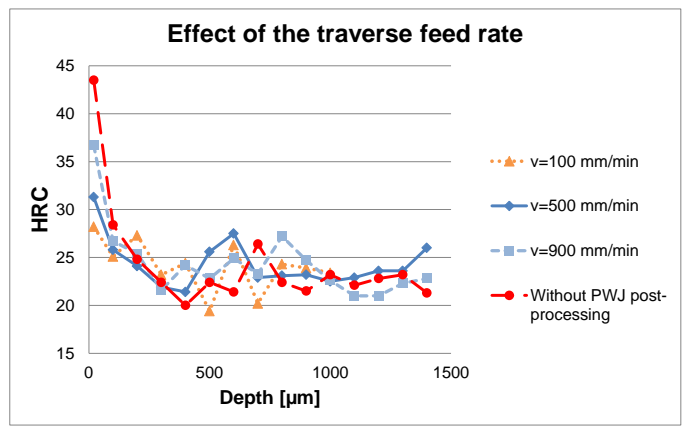

(c)

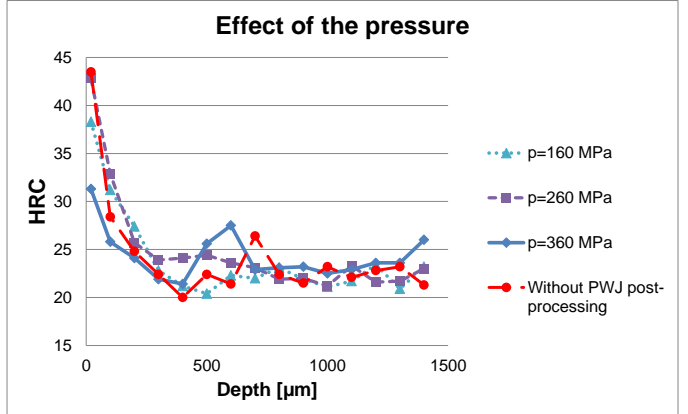

(b)

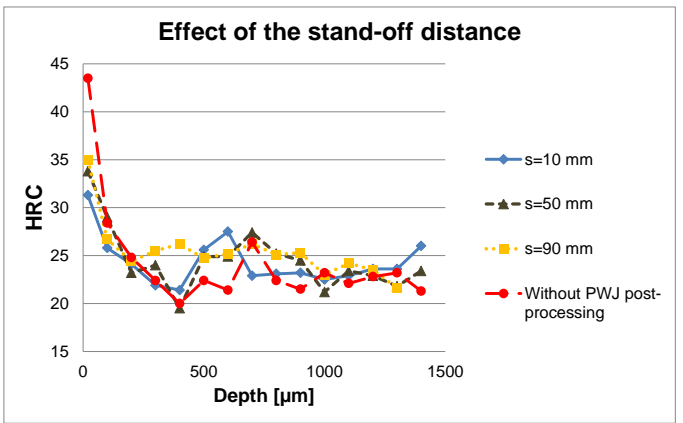

(d)

Figure 8. Effect of process parameters on the subsurface hardness in surfaces post-processed by PWJ: (a) abrasive mass flow rate; (b) pressure; (c) traverse feed rate; (d) stand-off distance.

Finally, the images obtained (Figure 9) and the chemical analysis done by the Energy Dispersive Spectrometer (EDS) reveal that there were no abrasive particles embedded in the surfaces. There are generally two types of embedment: deposited abrasives and submerged abrasives (Figure 10). The latter, are the most difficult to be removed according to Hashish [22]. However, thanks to the erosion produced by PWJ, the PWJ post-processing removed all abrasive particles embedded in the surfaces of Alloy 718 milled by AWJ. In submerged abrasives, the water droplets eroded first the metallic layer from the top of the particles, and then, removed the abrasive particle.

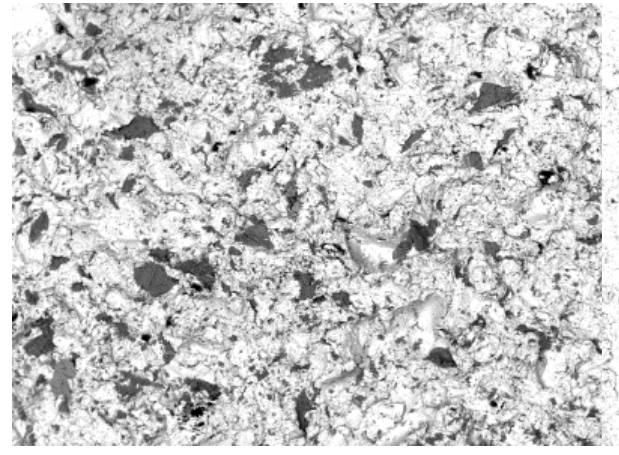

(a)

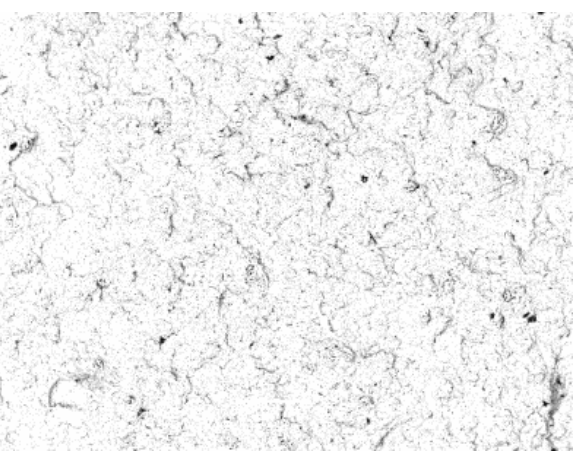

(b)

Figure 9. BEl images of: (a) AWJ milled surface; (b) PWJ post-processed surface 


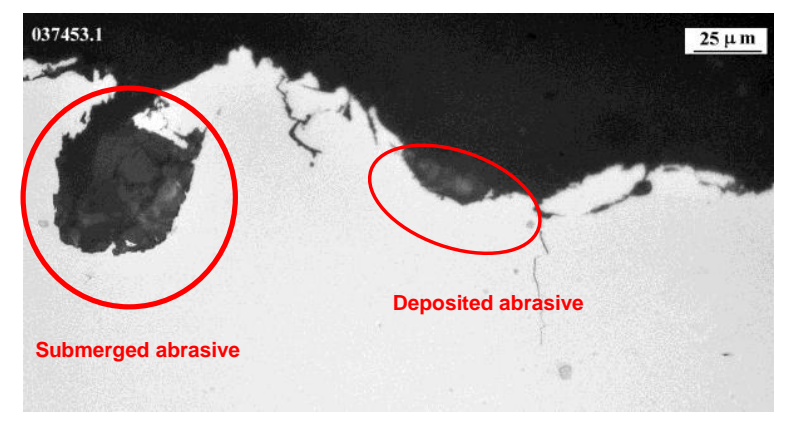

Figure 10. Submerged and deposited abrasive particles

\subsection{Effect of process AWJ milling and PWJ post processing in fatigue life}

Submerged and deposited abrasive particles

Figure 11 shows the results obtained in the fatigue tests. It is clearly seen that the AWJ milling process is detrimental for the fatigue life of the components. High surface roughness and the presence of abrasive particles are detrimental for the fatigue life of the components, which acts as a crack initiator. On the other hand, the compressive residual stresses induced by AWJ are beneficial for the fatigue life. Actually, Arola et al. [13] found AWJ peening conditions which improve the fatigue life of AISI 304L and Ti6Al4V components. However, in this study higher values of hydraulic energy were employed in order to obtain high MRR values for milling.

The PWJ post-processing does not improve the results, although it smoothens the surface, it is not able to repair the damage produced by the particles.

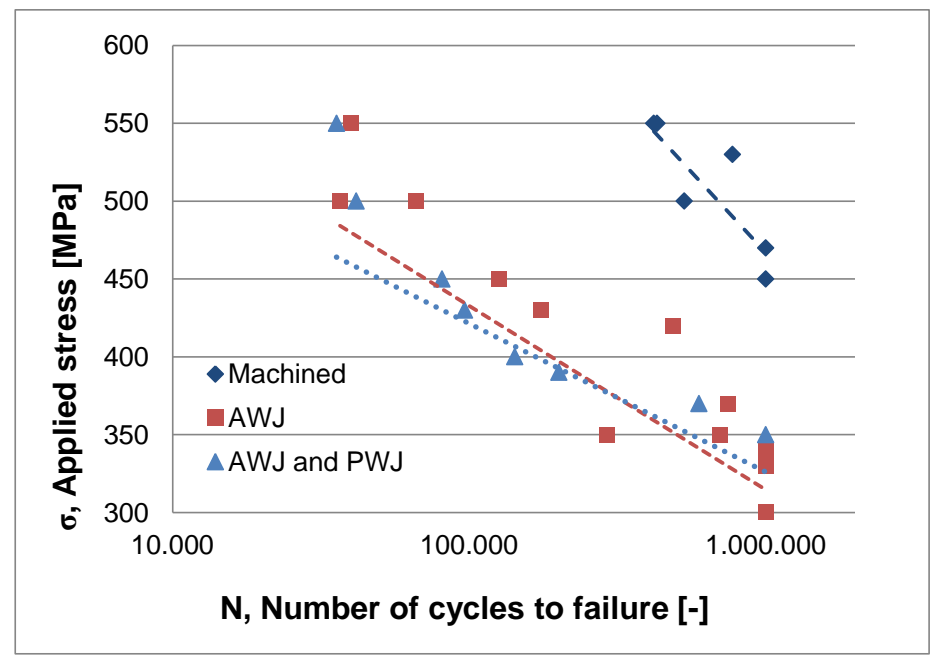

Figure 11. Maximum applied stress versus number of cycles to failure in the machined samples, and after applying the AWJ milling and the PWJ post-processing

As expected, the specimens fracture shows two differentiated areas revealing the operation of two chronologically spaced fracture mechanisms: Stage 1) Fatigue mechanism, where a smooth and dull texture is presented; and Stage 2) Ductile overload mechanism, where a rough texture and 45 shear lips are presented and occurred once the resistant section of the specimen was sufficiently reduced by the previous fatigue mechanism.

Fractographic analysis also shows differences between treated specimens and untreated specimens. The fracture morphology of the untreated specimens is coherent 
with fracture initiation at a unique location (Figure 12- a, b). Treated specimens, both AWJ and PWJ present a morphology coherent with the presence of multiple initiations. The presence of multiple initiations indicates a high stress concentration and, therefore, the presence of defects or imperfections (Figure 12-c).

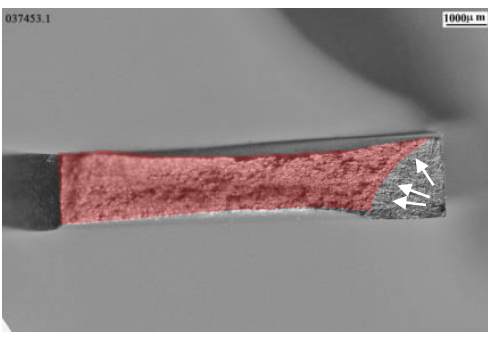

(a)

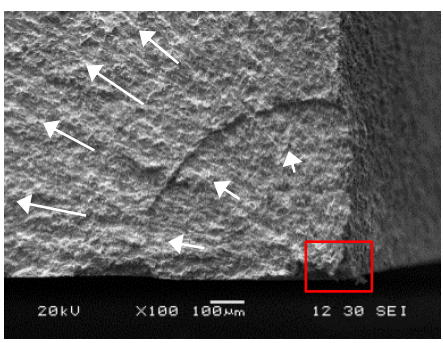

(b)

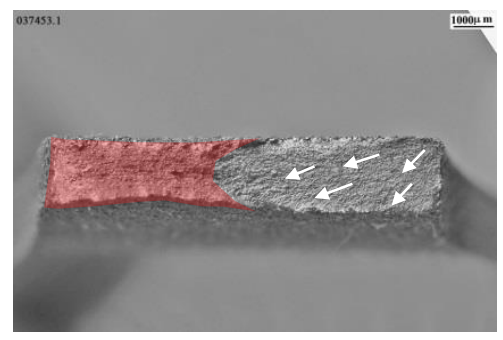

(c)

Figure 12. (a) macrograph of untreated specimen fracture surface; (b) SEM micrograph of fracture initiation of ungtreated specimen; (c) macrograph of specimen fracture surface treated by AWJ (red area: overload fracture; arrows: crack propagation direction)

The surface finish of the treated specimens presents a dull and rough surface, which is in contrast with the smoothness of untreated specimens. Surface of these samples are in fact formed by a continuous series of cavities or entries in the material. An inspection of the treated specimens' surface, by means of a stereoscopic microscope, reveals the presence of multiple secondary cracks. This presence of multiple secondary cracks, as the presence of multiple initiation of the fracture, indicates a high stress concentration and the presence of defects or imperfections. The fact that secondary cracks are located at areas of the surface with deeper cavities suggests that these are at the origin of the fracture.

The detection of multiple Ratchet marks found in treated specimens confirms the presence of multiple initiations (Figure 13). The analysis by backscattered electron imaging at initiations locations reveals the presence of embedded particles (Figure 14a) in the case of specimens treated by AWJ. These particles operate as nucleation sites. These particles, analyzed by Energy Dispersive X-ray Spectroscopy (EDS), are composed mainly of: $\mathrm{Si}, \mathrm{O}, \mathrm{Al}, \mathrm{Fe}$ and $\mathrm{Mg}$ (Figure 14-b), which is consistent with particles from the AWJ process. Therefore, particles from the AWJ process are operating as nucleation sites for fatigue cracks. In the case of specimens cleaned by PWJ, the cavities, generated by the embedment of particles (AWJ) that have been subsequently extracted (PWJ), served as nucleation sites (Figure 14-C).

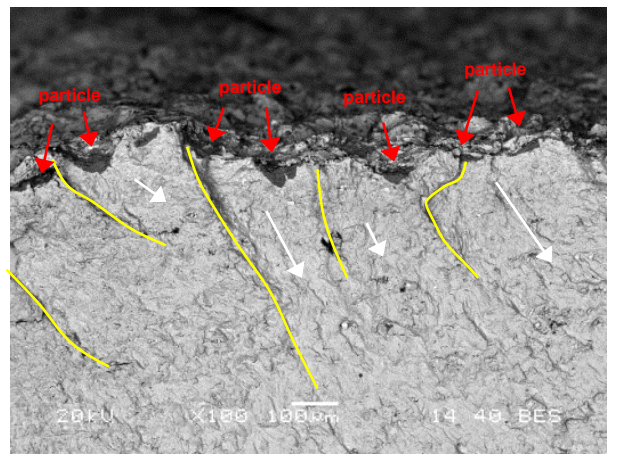

(a)

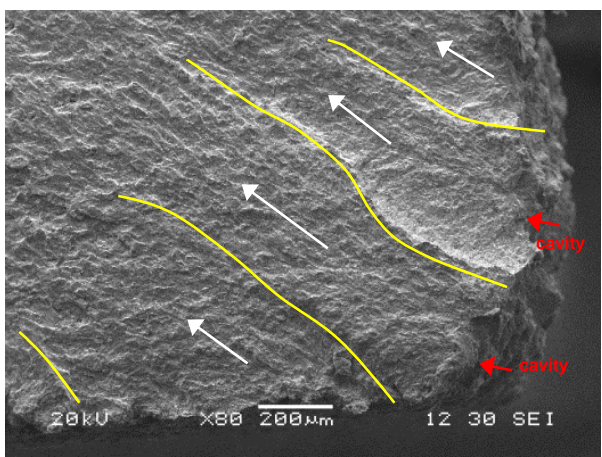

(b)

Figure 13. SEM micrograph of initiations originated at particles (Yellow line: Ratchet marks; White arrows: fatigue crack propagation direction): (a) specimen milled by $A W J$; (b)specimen cleaned by PWJ 


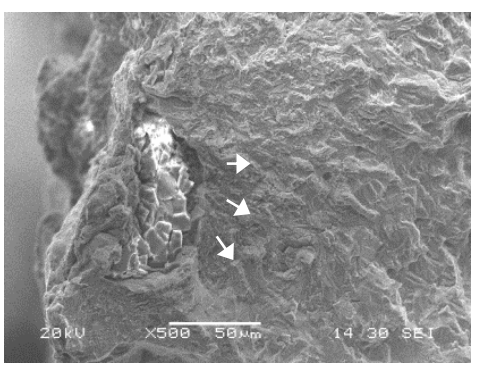

(a)

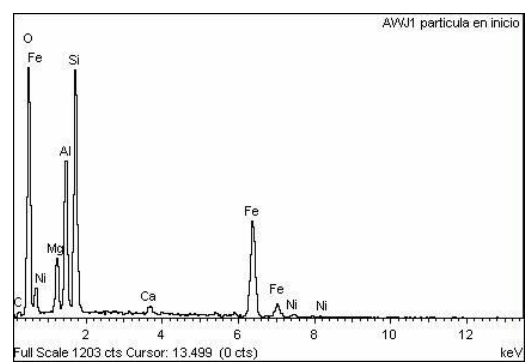

(b)

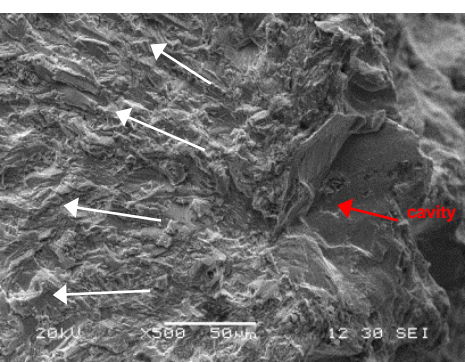

(c)

Figure 14. (a) SEM micrograph of a particle actuating a crack nucleation site in a specimen milled by AWJ; (b) EDS spectrum showing the nature of the particles at specimen treated by AWJ; (c)EDM micrograph of initiation originated at a cavity related to a particle that has been removed by PWJ.

Finally, the metallographic analysis performed by Light microscopy revealed that specimens subjected to PWJ and/or AWJ treatment present multiple secondary cracks. The secondary cracks are located at surface irregularities related to the AWJ or WJ process: cavities, concave areas and folds, which in some cases are filled with particles. These sharp and crack-like irregularities operate as stress raisers, and reach a depth of $120 \mu \mathrm{m}$ on AWJ specimens, and a depth up to $300 \mu \mathrm{m}$ on specimens cleaned by PWJ. The surface of untreated specimens, in comparison with treated specimens, is smooth and presents no irregularities. There are no secondary cracks on specimen surface. Finally, the microstructure is, as expected, formed by a gamma matrix with presence of niobium carbides and titanium carbonitrides. The microstructure at the surface $(20 \mu \mathrm{m})$ of the treated specimens evidences its deformation during AWJ or PWJ treatments.

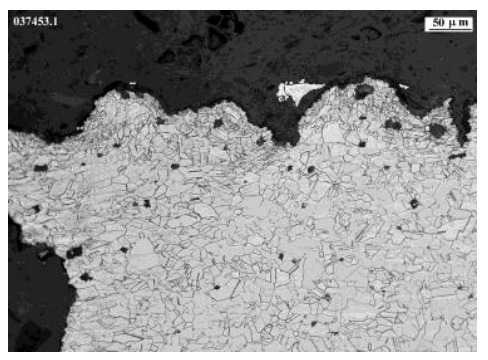

(a)

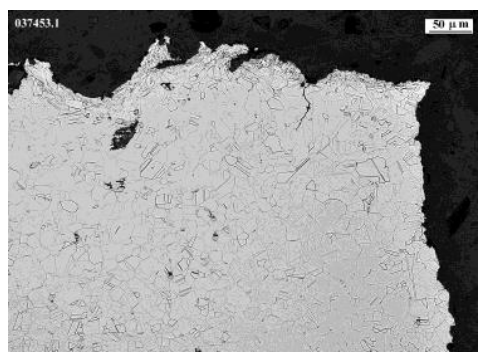

(b)

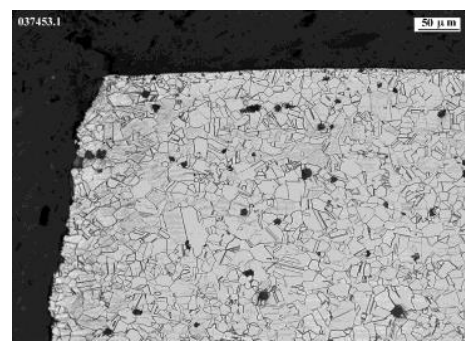

(c)

Figure 15. Light micrograph of fracture and surface of: (a) specimen milled by AWJ; (b)specimen cleaned by PWJ; (c) untreated specimen

\section{CONCLUSIONS}

The analysis of milled surfaces revealed that all surfaces have a homogeneous roughness in the transversal and the longitudinal directions, which varies from 8 to 16 $\mu \mathrm{m}$. In addition, all surfaces presented embedded abrasive particles, which can vary from $5 \%$ to $20 \%$ of the total surface area depending on process parameters. When increasing the pressure, the traverse feed rate and the stand-off distance, the area percentage with embedded abrasive particles increases. On the other hand, the abrasive mass flow rate does not show a clear effect on the area percentage with embedded abrasive particles. Finally, the milling process also produces a surface hardening of about 50\% with respect to the untreated bulk Alloy 718 (20-25 HRC), which may indicate a significant gradient of compressive residual stresses. In this case, no significant effects of process parameters were observed. 
The Plain Waterjet (PWJ) technology is applied for removing the abrasive particles embedded in the surfaces cut and milled by AWJ. For all tested conditions, this technology removed all the particles embedded in the surface. In addition, this process in general smoothened the surfaces produced by AWJ milling and it also released near-surface stress.

Finally, fatigue tests showed that under processing conditions used in this study, the AWJ process is detrimental for fatigue life of the components, since it produces high roughness and crack-like surface irregularities, which acts as a nucleation sites. Although removing abrasive particles, the cavities generated by the embedment of particles serve as nucleation sites. Even though residual stresses have not been measured, obtained fatigue results suggest that these are not significant or at least unable to overcome the effect of irregularities.

\section{ACKNOWLEDGEMENTS}

The authors acknowledge the support of the Ministry of Economy and Competitiveness of the Spanish Government for support of project EVOCA II (reference DPI201345308-P).

\section{REFERENCES}

1. Global Market Forecast 2016-2035 Airbus, Commercial Aircraft. http://www.airbus.com/company/market/global-market-forecast-2016-2035/.

Accessed 3 May 2017

2. Ezugwu EO (2005) Key improvements in the machining of difficult-to-cut aerospace superalloys. Int $\mathrm{J}$ Mach Tools Manuf 45:1353-1367. doi: 10.1016/j.jimachtools.2005.02.003

3. Ezugwu EO, Bonney J, Yamane $Y$ (2003) An overview of the machinability of aeroengine alloys. J Mater Process Technol 134:233-253. doi: 10.1016/S09240136(02)01042-7

4. Bayoun Q, Liang L, Ning H (2010) Effects of cooling/lubrication conditions on High-Speed Turning Ti6AI4V. Proc. 4th CIRP Int. Conf. High Perform. Cut.

5. N.(primero) Khanna, N., Sangwan, K.S. K (2010) Comparison of Cutting Tool Performance in Machining of Titanium Alloys and Inconel 718 Super Alloy. Proc. 4th CIRP Int. Conf. High Perform. Cut.

6. Klocke F, Sangermann H, Krämer A, Lung D (2011) Influence of a high-pressure lubricoolant supply on thermo-mechanical tool load and tool wear behaviour in the turning of aerospace materials.

7. Escobar-Palafox GA, Gault RS, Ridgway K (2012) Characterisation of Abrasive Water-jet Process for Pocket Milling in Inconel 718. Procedia CIRP 1:404-408. doi: 10.1016/j.procir.2012.04.072

8. Ay M, Çaydaş U, Hasçalik A (2010) Effect of Traverse Speed on Abrasive Waterjet Machining of Age Hardened Inconel 718 Nickel-Based Superalloy. Mater Manuf Process 25:1160-1165. doi: 10.1080/10426914.2010.502953 
9. Chen FL, Siores E, Patel K, Momber AW (2002) Minimising particle contamination at abrasive waterjet machined surfaces by a nozzle oscillation technique. Int $\mathrm{J}$ Mach Tools Manuf 42:1385-1390. doi: doi: DOI: 10.1016/S0890-6955(02)00081-0

10. (2009) Fatigue Testing of Abrasive Water Jet Cut Titanium. United States. Department of Energy

11. Huang L, Kinnell P, Shipway PH (2013) Parametric Effects on Grit Embedment and Surface Morphology in an Innovative Hybrid Waterjet Cleaning Process for Alpha Case Removal from Titanium Alloys. Procedia CIRP 6:594-599. doi: 10.1016/j.procir.2013.03.077

12. Arola D, McCain ML, Kunaporn S, Ramulu M (2001) Waterjet and abrasive waterjet surface treatment of titanium: a comparison of surface texture and residual stress. Wear 249:943-950. doi: doi: DOI: 10.1016/S00431648(01)00826-2

13. Arola D, Alade AE, Weber W (2006) Improving fatigue strength of metals using abrasive waterjet peening. Mach Sci Technol 10:197-218.

14. Azhari A, Schindler C, Godard C, et al (2016) Effect of multiple passes treatment in waterjet peening on fatigue performance. Appl Surf Sci 388, Part A:468-474. doi: 10.1016/j.apsusc.2015.11.195

15. Lieblich M, Barriuso S, lbáñez J, et al (2016) On the fatigue behavior of medical Ti6Al4V roughened by grit blasting and abrasiveless waterjet peening. J Mech Behav Biomed Mater 63:390-398. doi: 10.1016/j.jmbbm.2016.07.011

16. Sadasivam B, Hizal A, Arola D (2009) Abrasive waterjet peening with elastic prestress: A parametric evaluation. Int J Mach Tools Manuf 49:134-141. doi: 16/j.jjmachtools.2008.10.001

17. Shipway PH, Fowler G, Pashby IR (2005) Characteristics of the surface of a titanium alloy following milling with abrasive waterjets. Wear 258:123-132. doi: 10.1016/j.wear.2004.04.005

18. A. W. Momber, R. Kovacevic (1997) Principles of Abrasive Water Jet MAchining. Springer

19. Tazibt A, Parsy F, Abriak N (1996) Theoretical analysis of the particle acceleration process in abrasive water jet cutting. Comput Mater Sci 5:243-254. doi: 10.1016/0927-0256(95)00075-5

20. Alberdi A, Rivero A, L. N. López de Lacalle, et al (2010) Effect of process parameter on the kerf geometry in abrasive water jet milling. Int $\mathrm{J}$ Adv Manuf Technol 51:467-480. doi: 10.1007/s00170-010-2662-y

21. Taylor TA (1995) Surface roughening of metallic substrates by high pressure pure waterjet. Surf Coat Technol 76-77:95-100. doi: doi: 10.1016/02578972(95)02528-6

22. Hashish M (1991) Characteristics of Surfaces Machined With Abrasive-Waterjets. J Eng Mater Technol 113:354-362. doi: 10.1115/1.2903418 